\title{
Sol-Gel Synthesis of Mullite Starting from Different Inorganic Precursors
}

\author{
Lucia Téllez Jurado, ${ }^{1}$ Rosa María Arévalo Hernández, ${ }^{1}$ and Enrique Rocha-Rangel ${ }^{2}$ \\ ${ }^{1}$ ESIQIE-I P N, UPALM-Zacatenco, Lindavista, 07738 México, DF, Mexico \\ ${ }^{2}$ Universidad Autónoma Metropolitana, Avendia San Pablo 180, Colonia Reynosa-Tamaulipas, 02200 México, DF, Mexico \\ Correspondence should be addressed to Enrique Rocha-Rangel; erochar@upv.edu.mx
}

Received 17 March 2013; Revised 19 June 2013; Accepted 19 June 2013

Academic Editor: Thierry Barriere

Copyright ( 2013 Lucia Téllez Jurado et al. This is an open access article distributed under the Creative Commons Attribution License, which permits unrestricted use, distribution, and reproduction in any medium, provided the original work is properly cited.

\begin{abstract}
Using silicotetraetilortosilicate (TEOS) mixed with aluminum tri-sec-butoxide (TSBAI) or aluminum cloaures mullite ceramics were created by the sol-gel method. The quantities used of each substance were those that led to obtain stoichiometric mullite $\left(3 \mathrm{Al}_{2} \mathrm{O}_{3} \cdot 2 \mathrm{SiO}_{2}\right)$. The experimental methodology used for obtaining mullite consisted in: sol-gel synthesis of precursor materials, isothermal treatment of those materials, and characterization of resulting materials. In order to determine the advance of reactions during mullite formation, isothermal treatments between $300^{\circ} \mathrm{C}$ and $1600^{\circ} \mathrm{C}$ were performed, keeping the samples at each temperature during $4 \mathrm{~h}$. From XRD results, it may be said that precursor powders originally amorphous start to crystallize in $\mathrm{Al}_{2} \mathrm{O}_{3}$ and $\mathrm{SiO}_{2}$ at $1200^{\circ} \mathrm{C}$, and the mullite formation starts at $1200^{\circ} \mathrm{C}$, with being completed at $1600^{\circ} \mathrm{C}$. The use of TSBAI favors the formation of mullite crystals at lower temperature. From SEM observations a microstructure that presents primary mullite with randomly oriented grains of secondary mullite with acicular shapes and sizes that range between 1.25 and $1.50 \mu \mathrm{m}$ long may be determined.
\end{abstract}

\section{Introduction}

Materials from the $\mathrm{SiO}_{2}-\mathrm{Al}_{2} \mathrm{O}_{3}$ system play an important role in the development of traditional and advanced ceramics. Mullite, a material obtainable at atmospheric pressures, is part of this system. Mullite is a rare mineral not found in abundant quantities in nature; although most of traditional ceramics have it as part of their final composition for mineral aluminosilicates are regularly used for its manufacturing. The importance of mullite lies in its good mechanical, thermal, chemical, and electrical properties which remain under elevated temperatures (about $1500^{\circ} \mathrm{C}$ ) [1-3]. Conventionally, mullite is produced by high temperature calcination of mixtures of $\mathrm{SiO}_{2}$ and $\mathrm{Al}_{2} \mathrm{O}_{3}$ [4]. The activation of energy for ion diffusion that takes place through the network of energy requires high temperatures; therefore, high sintering temperatures are required $\left(>1700^{\circ} \mathrm{C}\right)$ to obtain dense bodies of mullite [5]. Moreover, the sol-gel process enables the production of amorphous and polycrystalline materials with special characteristics starting from submicron powders of high purity [6-8]. Its usefulness lies in the fact that it requires low temperatures to obtain dense bodies compared to traditional manufacturing methods by fusion [6-8]. One of the many uses of mullite takes place in the electronics industry where it is used as substrate $[1,3]$. A substrate is the support on which an electronic circuit, consisting of conductors, dielectrics, and integrated components, is mounted. The choice of substrate depends on the thermal, mechanical, and electrical characteristics of the circuit. Based on the above, the aim of this research is the development and characterization of mullite ceramics by the sol-gel method, in search of its applications as a substrate in electronics.

\section{Experimental}

The following experimental methodology for obtaining mullite consisted in the following steps.

(i) Sol-gel synthesis of the mullite precursor materials. 
TABLE 1: Reagents and their function in obtaining mullite.

\begin{tabular}{lccc}
\hline Function & Reagents & Formula & Trademark \\
\hline Precursor & Silicon tetraethy lorthosilicate & (TEOS) & Sigma-Aldrich \\
Precursor & Aluminum alkoxide, Aluminum tri-sec-butoxide & $($ TSBAI) & Sigma-Aldrich \\
Precursor & Aluminum chloride & $\left(\mathrm{AlCl}_{3}\right)$ & Sigma-Aldrich \\
Thinner & Isopropanol & $(2-$ propanol) & JT Baker \\
Hydrolyzing agent & Deionized water & $\mathrm{H}_{2} \mathrm{O}$ & $\mathrm{JT} \mathrm{Baker}$ \\
Catalyst & Hydrochloric acid & $(\mathrm{HCl})$ & \\
\hline
\end{tabular}

(ii) Heat treatment of these materials for producing mullite.

(iii) Characterization of both materials: precursors and heat-treated.

2.1. Synthesis of Precursor Materials. The synthesis of precursor materials was carried out using the reagents indicated in Table 1. The role of each is also mentioned. Considering that the TEOS-TSBAI precursors were used for obtaining sample 1 and for obtaining sample 2, a mixture of TEOS- $\mathrm{AlCl}_{3}$ precursors was used.

The composition of mullite precursors was aimed at the stoichiometric relation: $3 \mathrm{Al}_{2} \mathrm{O}_{3} \cdot 2 \mathrm{SiO}_{2}$. Sample 1 was prepared using aluminum alkoxide (TSBAI) as a precursor of alumina, and sample 2 was prepared using aluminum chloride $\left(\mathrm{AlCl}_{3}\right)$ also as precursor of alumina. In both samples the silica precursor was tetraethyl orthosilicate (TEOS).

2.2. Hydrolysis Condensation. The synthesis was carried out as follows.

(i) The solutions were prepared at room temperature; they were kept separately and stirred magnetically continuously for fifteen minutes for homogenization.

(ii) A three-necked flask was placed in a thermostatic bath and heated at a constant temperature of $80^{\circ} \mathrm{C}$.

(iii) Solution 1 was added in the three necked flask and mechanically stirred at $600 \mathrm{rpm}$ during 20 minutes.

(iv) Afterwards, the solution was added drop by drop to the hydrolyzing flask, while the stirring continued, till the end; the solution was stirred for 10 more minutes.

(v) Subsequently, the solution was divided into 5 equal parts. Each part was added to the three-necked flask every 5 minutes.

(vi) After the last addition of the solution to the threenecked flask, the solution was kept in constant agitation for 10 minutes.

(vii) Upon completion of the reaction time, the solution was poured into a polypropylene container and was hermetically sealed for gelation.

2.3. Aging. The gelation process in the hermetically sealed container made of polypropylene consisted in reviewing and withdrawing the expelled liquid exudates (water, alcohol and acid) daily. This was done for 20 consecutive days, noting that

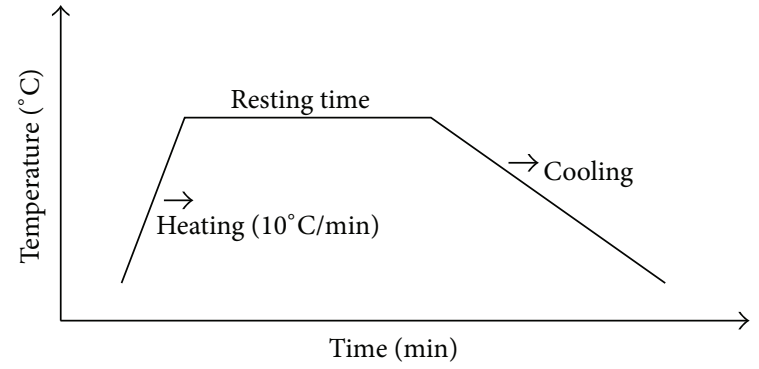

FIGURE 1: Heat treatment cycle.

during the last days the release of the remaining liquid was zero.

2.4. Drying. After the aging step, containers were partially opened very slowly for the solvent to evaporate and for the gel to dry up to a constant weight. This process was carried out at room temperature. Evaporation of the solvents was done very slowly in order to obtain powders. Finally, mullite precursor materials were dried at a temperature of $120^{\circ} \mathrm{C}$ for 8 days more.

2.5. Isothermal Treatment. Heat treatments for the study of the transformation phase of precursors to mullite materials were conducted in an electric furnace. The samples were placed in a sample holder of sintered high purity alumina. Figure 1 shows the isothermal process that was undergone by mullite precursor materials.

Figure 1 shows three zones.

(i) Zone 1: stage of heating at a rate of $10^{\circ} \mathrm{C} / \mathrm{min}$ to reach desired temperature $\left(300^{\circ} \mathrm{C}\right.$ to $\left.1600^{\circ} \mathrm{C}\right)$.

(ii) Zone 2: resting time of the material within the furnace (4 and 8 hours).

(iii) Zone 3: furnace cooling period to room temperature with a cooling rate of $10^{\circ} \mathrm{C} / \mathrm{min}$.

2.6. Samples Characterization. To perform the characterization of the samples the following techniques were used: X-ray diffraction (XRD), infrared spectroscopy by Fourier transform (FT-IR), and scanning electron microscopy (SEM). These techniques were used in order to gather data about their chemical composition (physicochemical, thermal, and microstructural analyses). 


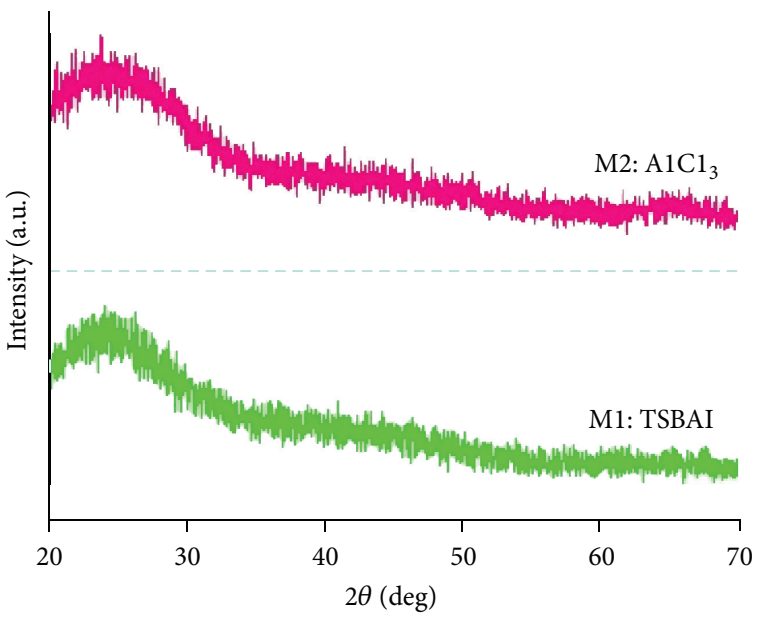

FIGURE 2: X-ray diffraction spectra of mullite precursor materials synthesized with TSBAI and $\mathrm{AlCl}_{3}$ and dried at $110^{\circ} \mathrm{C}$.

\section{Results and Discussion}

3.1. Chemical and Crystalline Structure of Mullite Precursor Materials. The mullite precursor materials were obtained in powder. These powders were compacted and heat-treated for conversion to mullite. Figure 2 shows the spectra of $\mathrm{X}$ ray diffraction of the mullite precursor material synthesized with TSBAI and $\mathrm{AlCl}_{3}$ and dried at $110^{\circ} \mathrm{C}$. Figure 2 shows that mullite precursor materials have a short-range structure, independently of the type of aluminum precursor used. The broad peak with a maximum located at $\sim 24^{\circ}$ in 2 theta, represents the presence of vitreous silica $\left(\mathrm{SiO}_{2}\right)$.

Figure 3 shows the FT-IR spectra of the synthesized mullite precursor materials with TSBAI (M1) and $\mathrm{AlCl}_{3}$ (M2), dried at $110^{\circ} \mathrm{C}$. In M1 sample, a shoulder can be observed at very low absorption intensity at $1161 \mathrm{~cm}^{-1}$ which corresponds to the formation of mullite. The formation of silica is evidenced by the appearance of a band at $1090 \mathrm{~cm}^{-1}$ corresponding to the $\mathrm{Si}-\mathrm{O}-\mathrm{Si}$ bond. Two absorption bands are assigned to the $\mathrm{Si}-\mathrm{O}-\mathrm{Al}$ bond, observed at 820 and $791 \mathrm{~cm}^{-1}$, suggesting that the aluminum forms a covalent-ionic bond with the $\mathrm{Si}-\mathrm{O}$ bond during the hydrolysis-condensation reaction of the silicon alkoxides such as aluminum, forming $\mathrm{Si}-\mathrm{O}-\mathrm{Al}$ bonds in the presence of alumina and silicon oxide in the synthesized material. The band at $729 \mathrm{~cm}^{-1}$ was assigned to the group of $\mathrm{Al}$ and/or Si tetrahedral, $\left[\mathrm{AlO}_{4}\right]$ and/or $\left[\mathrm{SiO}_{4}\right]$, by its vibration mode. The absorption band derived from Al-O bond was observed at $635 \mathrm{~cm}^{-1}$ [9-11]. In M2 sample, the absorption band observed at $1060 \mathrm{~cm}^{-1}$ was assigned to the $\mathrm{Si}-\mathrm{O}-\mathrm{Si}$ bond; this band is seen shifted to a lower wave number, with respect to the $1080 \mathrm{~cm}^{-1}$ of $\mathrm{SiO}_{2}$; this is due to the structure formed from the different precursors. The tetrahedral Al-O bond of lengthening was observed at $922 \mathrm{~cm}^{-1}$ and the absorption band observed at $779 \mathrm{~cm}^{-1}$ was assigned to the bending vibration of the tetrahedral $\mathrm{Al}$ or $\mathrm{Si}$, $\left[\mathrm{AlO}_{4}\right]$ and/or $\left[\mathrm{SiO}_{4}\right][9-11]$.

3.2. Chemical and Crystalline Structure of Sintered Samples. Figures 4 and 5 show the X-ray diffraction spectra of

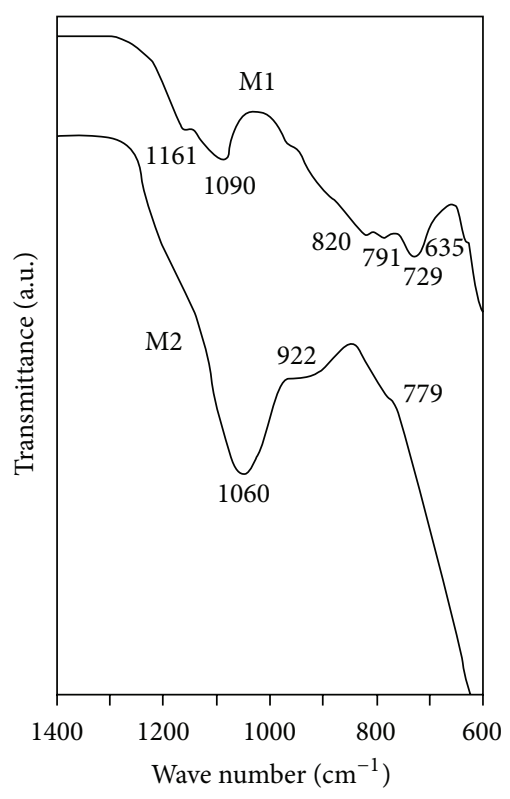

FIGURE 3: FT-IR spectra of mullite precursor materials synthesized with TSBAI (M1) and $\mathrm{AlCl}_{3}$ (M2).

mullite precursor samples synthesized with TSBAI and $\mathrm{AlCl}_{3}$, respectively, and thermally treated in the range of $300^{\circ} \mathrm{C}$ to $1000^{\circ} \mathrm{C}$. Figure 4 shows that in the temperature range of $300^{\circ} \mathrm{C}$ to $600^{\circ} \mathrm{C}$ the material retains its short-range structure. By increasing the temperature to $900^{\circ} \mathrm{C}$, the material starts to crystallize, which is indicated by the presence of small diffraction peaks: two of these are located at $23^{\circ}$ and $46^{\circ}$ in two theta; and correspond to characteristic peaks of kyanite $\left(\mathrm{Al}_{2} \mathrm{SiO}_{5}\right)$; a third peak is located at $67^{\circ}$ in two theta, and this refers to the peaks of stishovite $\left(\mathrm{SiO}_{2}\right)$. It is observed that at $1000^{\circ} \mathrm{C}$ the intensity of the peaks continues to increase, which means that the increase in temperature favors the phase crystallization. In this spectrum four peaks in particular are highlighted: one at $22.3^{\circ}$ that corresponds to cristobalite $\left(\mathrm{SiO}_{2}\right)$, two more localized at $37.6^{\circ}$ and $46^{\circ}$ corresponding to kyanite, and a fourth peak located at $67.6^{\circ}$ corresponding to stishovite.

Figure 5 shows that the material synthesized with $\mathrm{AlCl}_{3}$ retains its short-range structure when it is treated at temperatures between $300^{\circ} \mathrm{C}$ and $600^{\circ} \mathrm{C}$, which was also observed in materials synthesized with TSBAI. At temperatures of $900^{\circ} \mathrm{C}$ to $1000^{\circ} \mathrm{C}$ the formation of small localized diffraction peaks at 23,46 , and $67^{\circ}$ is shown. The first is characteristic of the presence of cristobalite, the second refers to kyanite, and the latter corresponds to stishovite. Comparing this sample with the previous one, it may be said that the phase formation takes place at a much lower temperature.

Figures 6 and 7 show the XRD spectra mullite precursor samples synthesized with TSBAI and $\mathrm{AlCl}_{3}$, respectively, and thermal-treated in the range of $1200^{\circ} \mathrm{C}$ to $1600^{\circ} \mathrm{C}$. Figure 6 shows that the sample prepared with TSBAI presents a crystal structure, with well-defined peaks corresponding to the temperature of $1200^{\circ} \mathrm{C}$, where the mullite formation is observed by the appearance of faint peaks at 26.2, 26.7, 31.3, 


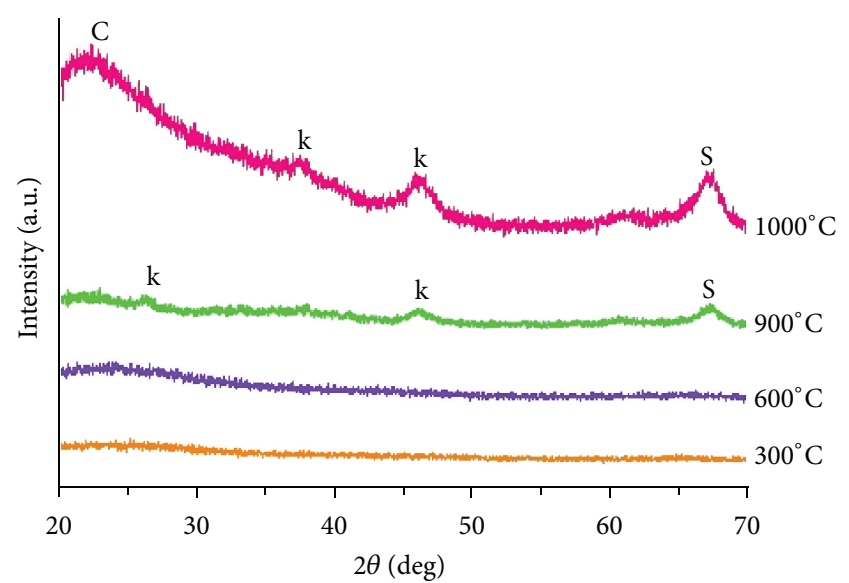

k: cyanite

C: cristobalite

S: stishovite

FIGURE 4: XRD spectra of synthesized samples with TSBAI and thermally treated in the range of $300^{\circ} \mathrm{C}$ to $1000^{\circ} \mathrm{C}$.

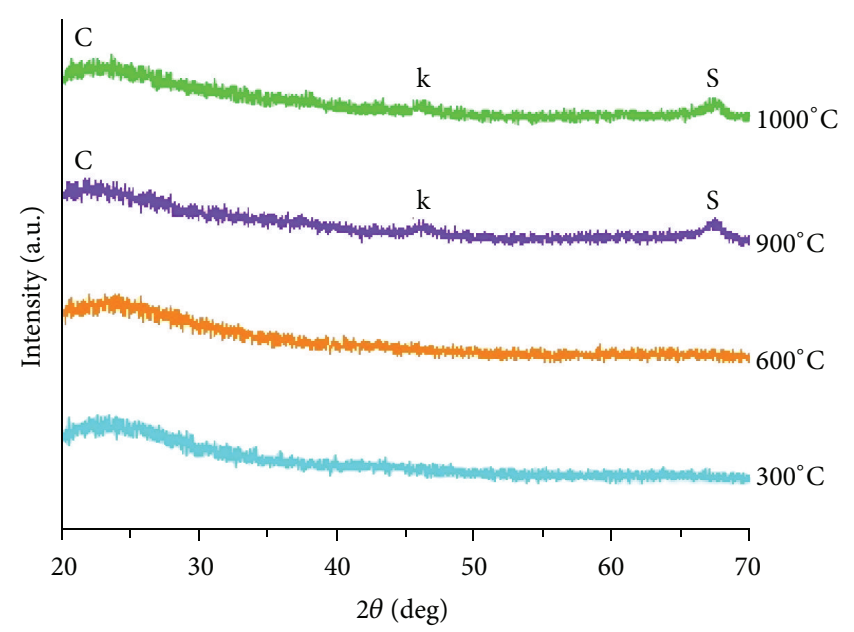

k: cyanite

C: cristobalite

S: stishovite

FIgURE 5: XRD spectra of synthesized samples with $\mathrm{AlCl}_{3}$ and thermally treated in the range of 300 to $1000^{\circ} \mathrm{C}$.

$33.6,35.5,39.6,41.2,42.9,54.3,57.8,61,64$, and $66.8^{\circ}$ in two theta. Moreover, the presence of three phases such as, cristobalite with characteristic peaks at $23^{\circ}$ and $68.4^{\circ}$, silicon oxide with a peak at $38.1^{\circ}$, and finally corundum $\left(\mathrm{Al}_{2} \mathrm{O}_{3}\right)$ with characteristic peaks at $25.8,43.6$ and $52.9^{\circ}$. At $1300^{\circ} \mathrm{C}$ all above mentioned peaks are observed, and peak intensity increases steadily which is a characteristic of cristobalite at $23^{\circ}$ in two theta. At $1400^{\circ} \mathrm{C}$ and $1500^{\circ} \mathrm{C}$ increments in peak intensity are observed. However, at $1600^{\circ} \mathrm{C}$ the disappearance of peaks of cristobalite, corundum, and silicon oxide is observed, because cristobalite $\left(\mathrm{SiO}_{2}\right)$ and silicon oxide react with corundum $\left(\mathrm{Al}_{2} \mathrm{O}_{3}\right)$ favoring mullite formation, so those peaks characteristic of mullite are more intense at $1600^{\circ} \mathrm{C}$.

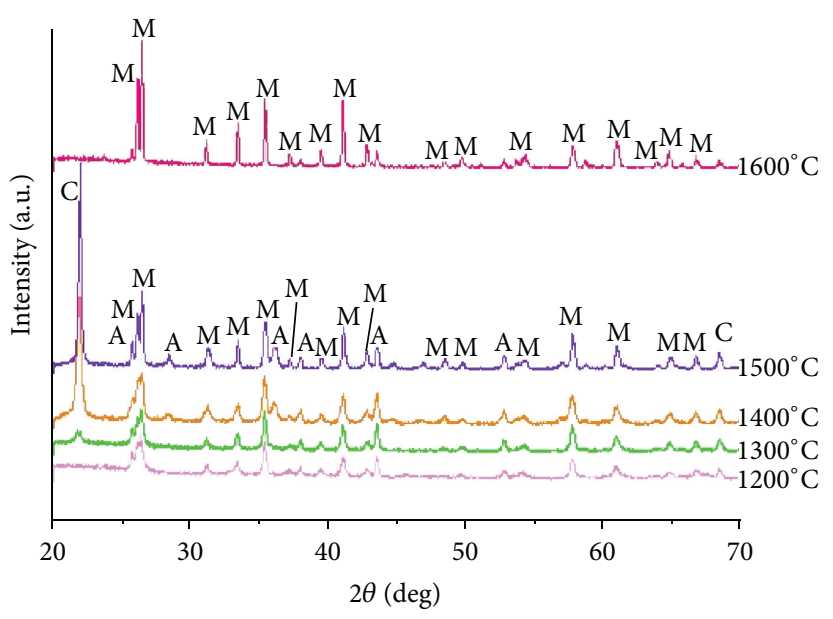

M: mullite
A: alumina
C: cristobalite

FIGURE 6: XRD spectra of synthesized samples with TSBAl and thermally treated in the range of $1200^{\circ} \mathrm{C}$ to $1600^{\circ} \mathrm{C}$.

Figure 7 shows the sample prepared with $\mathrm{AlCl}_{3}$ and thermal treated in the range of $1200^{\circ} \mathrm{C}$ to $1600^{\circ} \mathrm{C}$. The spectrum at $1200^{\circ} \mathrm{C}$ in Figure 7 shows low intensity and broad diffraction peaks similar to the samples treated at $900^{\circ} \mathrm{C}$ and $1000^{\circ} \mathrm{C}$ (Figure 6) unlike the sample prepared with TSBAI and treated at $1200^{\circ} \mathrm{C}$ which presents well-defined peaks. It still presents very low intensity peaks; four correspond to the formation of kyanite with characteristic peaks in 26, $35.5,57.8$, and $67.4^{\circ}$ and two peaks at $43.7^{\circ}$ and $46^{\circ}$ in two theta, corresponding to the presence of stishovite (allotropic form of $\mathrm{SiO}_{2}$ ). At $1300^{\circ} \mathrm{C}$, the formation of the characteristic peaks of mullite is observed; however, these peaks present low intensity. At $1400^{\circ} \mathrm{C}$ and $1500^{\circ} \mathrm{C}$ the mullite peaks increase their intensity. At $1400^{\circ} \mathrm{C}$ the cristobalite peak at $22^{\circ}$ in 2 theta reaches its greatest intensity, and at $1500^{\circ} \mathrm{C}$ it begins to decrease. The reason for this is that cristobalite $\left(\mathrm{SiO}_{2}\right)$ reacts with corundum $\left(\mathrm{Al}_{2} \mathrm{O}_{3}\right)$ favoring the formation of mullite. Therefore, at $1600^{\circ} \mathrm{C}$ total formation of mullite is shown. In this material the presence of mullite was evident at $1300^{\circ} \mathrm{C}$ indicating that the use of $\mathrm{AlCl}_{3}$ as a precursor of the $\mathrm{Al}_{2} \mathrm{O}_{3}$ source delays the formation of mullite in $100^{\circ} \mathrm{C}$ unlike when an alkoxide of $\mathrm{Al}$ is used.

FT-IR spectra of the M1 sample synthesized with TSBAI in Figure 8 show the evolution of the formation of mullite from the sample without heat treatment to the sample heattreated at $1600^{\circ} \mathrm{C}$. In this figure, two absorption bands with maximums at 886 and $1014 \mathrm{~cm}^{-1}$, corresponding to Al-O and $\mathrm{Si}-\mathrm{O}$ tetrahedral bonds and $\mathrm{Si}-\mathrm{O}-\mathrm{Si}$ bonds, respectively, are seen at $300^{\circ} \mathrm{C}$. These absorption bands are shifted to lower wave numbers than those for the sample without heat treatment. As the temperature increases, it may be observed that in spectra of $600,900,1000$, and $1200^{\circ} \mathrm{C}$ there are a shift and a change in shape of the bands that correspond to Al-O and $\mathrm{Si}-\mathrm{O}-\mathrm{Si}$ bonds, due to a rearrangement in the material structure by thermal treatment effect. At $900^{\circ} \mathrm{C}$ and $1000^{\circ} \mathrm{C}$ it 


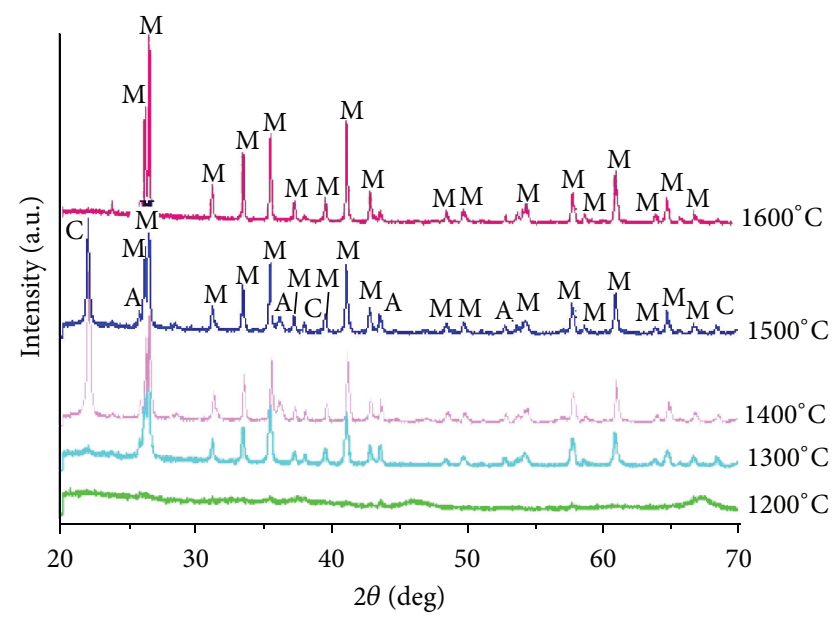

M: mullite

A: alumina

C: cristobalite

FIGURE 7: XRD spectra of synthesized samples with $\mathrm{AlCl}_{3}$ and thermal treated in the range of $1200^{\circ} \mathrm{C}$ to $1600^{\circ} \mathrm{C}$.

may be observed that the maximum of the band at $1014 \mathrm{~cm}^{-1}$ in the spectra of $300^{\circ} \mathrm{C}$ is shifted to $1080 \mathrm{~cm}^{-1}$. Spectra $1200,1300,1400$ and $1500^{\circ} \mathrm{C}$ are similar. In these spectra five absorption bands localized at 1164, 1104, 845, 750 and $635 \mathrm{~cm}^{-1}$ are found. The absorption band at $1064 \mathrm{~cm}^{-1}$ is assigned to vibration of the Al-O bond, the $\mathrm{Si}-\mathrm{O}$ bond is present at $1104 \mathrm{~cm}^{-1}$, two bands characteristic of the mullite formation are observed at 845 and $750 \mathrm{~cm}^{-1}$, the last band that appears at $635 \mathrm{~cm}^{-1}$ is assigned to vibration of the Al$\mathrm{O}$ octahedral bond. As may be seen from these results, the presence of absorption bands corresponding to the formation of mullite are present from $1200^{\circ} \mathrm{C}$, in agreement with XRD results. Finally, at 1400 and $1500^{\circ} \mathrm{C}$ an absorption band at $788 \mathrm{~cm}^{-1}$ assigned to the presence of Al-O or Si-O tetrahedral $\left[\mathrm{AlO}_{4}\right]$ and $\left[\mathrm{SiO}_{4}\right]$ is present. The spectrum of $1600^{\circ} \mathrm{C}$ is similar to the spectrum of $1500^{\circ} \mathrm{C}$ with the difference that the band at $788 \mathrm{~cm}^{-1}$ assigned to $\mathrm{Si}-\mathrm{O}$ bond that corresponds to the cristobalite is no longer seen. This agrees with the results of XRD where, at $1600^{\circ} \mathrm{C}$, the formation of mullite with little alumina presence is observed. In this spectrum $\left(1600^{\circ} \mathrm{C}\right)$ the absorption bands corresponding to mullite, located at $1164,1104,845,750$ and $635 \mathrm{~cm}^{-1}$, discussed above may be observed. According to the above, it may be said that the M1 sample synthesized with TSBAI shows the formation of mullite at a temperature of $1200^{\circ} \mathrm{C}$. This is transformed completely at $1500^{\circ} \mathrm{C} / 8 \mathrm{~h}$ or $1600^{\circ} \mathrm{C} / 4 \mathrm{~h}$. This agrees with the analysis of X-ray diffraction.

FT-IR spectra of the M2 sample synthesized with $\mathrm{AlCl}_{3}$ in Figure 9 show the evolution of the mullite formation from the sample without heat treatment to the sample heat-treated at $1600^{\circ} \mathrm{C}$. Figure 9 shows an absorption band with a peak at $1080 \mathrm{~cm}^{-1}$ assigned to Si-O-Si bond characteristic of the tetrahedron of $\left[\mathrm{SiO}_{4}\right]$ at $300^{\circ} \mathrm{C}$. The spectra at 600,900 , 1000 , and $1200^{\circ} \mathrm{C}$ are similar. In these spectra, there are two

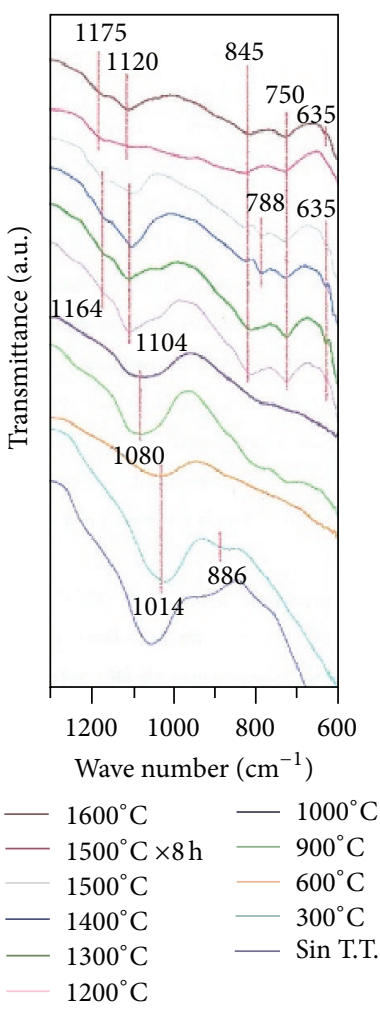

FIGURE 8: FT-IR spectra of the samples synthesized with TSBAI and heat-treated at 300 to $1600^{\circ} \mathrm{C}$.

localized absorption bands at 1080 and $781 \mathrm{~cm}^{-1}$. The first band shows small shifts to the right and left in the same location represented in the Si-O-Si bond present at $300^{\circ} \mathrm{C}$. The band formed at $781 \mathrm{~cm}^{-1}$ is assigned to Al-O or Si$\mathrm{O}$ tetrahedral bond $\left[\mathrm{AlO}_{4}\right]$ and $\left[\mathrm{SiO}_{4}\right]$. In the spectrum at $1200^{\circ} \mathrm{C}$ a third band at $717 \mathrm{~cm}^{-1}$ is observed that represents the Al-O octahedral bond. The spectra at 1300, 1400, and $1500^{\circ} \mathrm{C}$ have six absorption bands localized at 1241, 1175, $1120,845,750$ and $634 \mathrm{~cm}^{-1}$. The observed band at $1241 \mathrm{~cm}^{-1}$ is assigned to the vibration of the Si-O bond. Four bands, characteristic of mullite formation, are observed at 1175, 1120, 845 and $750 \mathrm{~cm}^{-1}$. The last band at $634 \mathrm{~cm}^{-1}$ is assigned to the vibration mode of the Al-O octahedral bond. The spectrum at $1600^{\circ} \mathrm{C}$ shows five absorption bands: four are characteristic mullite bands present at $1175,1120,845$, and $750 \mathrm{~cm}^{-1}$, and the last band at $634 \mathrm{~cm}^{-1}$ represents the Al-O octahedral bond. The spectrum of $1500^{\circ} \mathrm{C} / 8 \mathrm{~h}$ shows similarity with the spectrum of $1500^{\circ} \mathrm{C} / 4 \mathrm{~h}$. In the analysis of the M2 sample synthesized with $\mathrm{AlCl}_{3}$ the formation of mullite from $1300^{\circ} \mathrm{C}$ is observed. In addition, it was observed that the increase in the residence time of the sample in the heat treatment $\left(1500^{\circ} \mathrm{C} / 8 \mathrm{~h}\right)$ does not favor the total formation of mullite, which agrees with the results of X-ray diffraction, previously analyzed.

3.3. Microstructure. Figure 10 shows a micrograph taken with a SEM of the M1 sample synthesized with TSBAI and heattreated at $1500^{\circ} \mathrm{C} / 8 \mathrm{~h}$. This micrograph shows the massive 


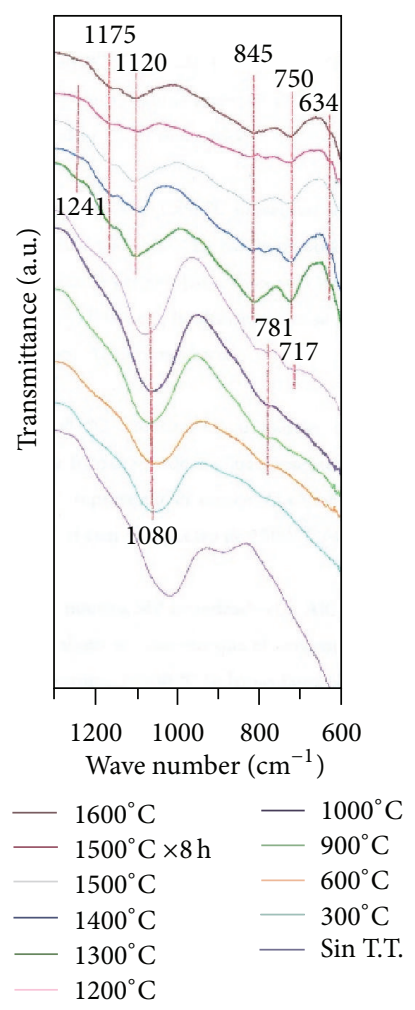

FIGURE 9: FT-IR spectra of the samples synthesized with $\mathrm{AlCl}_{3}$ and heat-treated at 300 to $1600^{\circ} \mathrm{C}$.

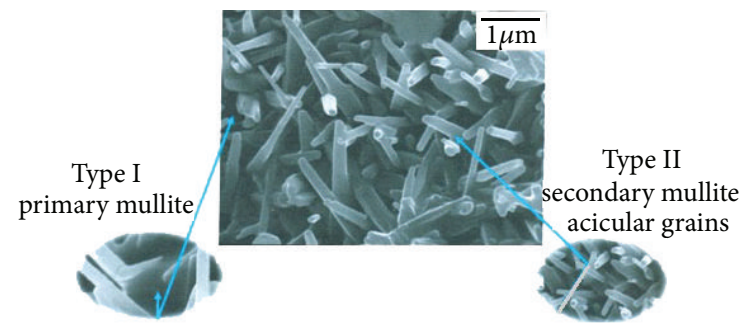

FIGURE 10: Micrograph taken with a SEM of the M1 sample synthesized with TSBAI and heat-treated at $1500^{\circ} \mathrm{C} / 8 \mathrm{~h}$. (a) Inner sample; (b) magnified inner sample.

formation of type II secondary mullite acicular grains with a random orientation, obtaining an average grain size of $\sim 1.5 \mu \mathrm{m}$ long and $0.25 \mu \mathrm{m}$ wide. These mullite grains are embedded in a network of primary mullites. The random orientation with respect to length size of grain and towards the left from the mullite matrix type I, generates porosity between the grains as shown in the cavity in Figure 10(b). The density of this M1 sample is high due to narrow accommodation of the acicular mullite crystalline grains. These results agree with those obtained by XRD with the presence of total mullite and in FT-IR with the unique formation of the characteristic bands of mullite.

Figure 11 shows the morphology of the $\mathrm{M} 2$ sample synthesized with $\mathrm{AlCl}_{3}$ and heat-treated at $1500^{\circ} \mathrm{C} / 8 \mathrm{~h}$. This micrograph shows the formation of secondary mullite acicular grains with a random orientation, obtaining an average grain

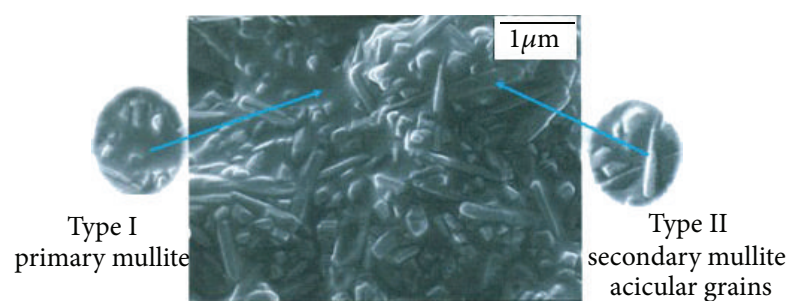

FIGURE 11: Micrograph taken with a SEM of the M2 sample synthesized with $\mathrm{AlCl}_{3}$ and heat-treated at $1500^{\circ} \mathrm{C} / 8 \mathrm{~h}$. (a) Inner sample; (b) magnified inner sample.

size of $\sim 1.25 \mu \mathrm{m}$ long and $0.25 \mu \mathrm{m}$ wide. These grains are embedded in a network of primary mullite, in which the grain size is heterogeneous thus decreasing the density and increasing porosity of the material, due to the same grain size difference [12].

\section{Conclusions}

(i) According to FT-IR results, the sample synthesized with TSBAI without heat treatment presents the formation of Si-O-Al bonds due to the presence of alumina and silica, whereas the sample synthesized with $\mathrm{AlCl}_{3}$ without heat treatment presents the formation of Si-O-Si and Al-O bonds corresponding to cristobalite and corundum, respectively. This corroborates that mullite is present from the synthesis stage (hydrolysis-condensation).

(ii) Based on the results of XRD and FT-IR, the onset of crystallization of mullite was obtained at $1200^{\circ} \mathrm{C}$ in the sample synthesized with aluminum alkoxide (TSBAI), taking advantage of $100^{\circ} \mathrm{C}$ compared to the sample synthesized with aluminum chloride $\left(\mathrm{AlCl}_{3}\right)$.

(iii) Based on the XRD, FT-IR and SEM results and comparing the two samples obtained at $1600^{\circ} \mathrm{C} / 4 \mathrm{~h}$, the sample synthesized with TSBAI presents mullite, corundum, and minimal cristobalite formation, while the sample synthesized with $\mathrm{AlCl}_{3}$ only presents the formation of mullite and corundum.

\section{References}

[1] A. I. Aksay and M. S. Wiederhorn, "Symposium for Mullite processing, structure and properties, topical issue," Journal of the American Ceramic Society, vol. 74, no. 10, p. 2341, 1991.

[2] M. D. Sacks and J. A. Pask, "Sintering of mullite-containing materials: y effect of composition," Journal of the American Ceramic Society, vol. 65, no. 2, pp. 65-70, 1982.

[3] O. H. Wyatt and D. Dew Hughes, "Metals ceramics and polymers and properties of engineering materials," 2000.

[4] H. Schneider, K. Okada, and J. Pask, "Mullite and mullite ceramics," Journal of the American Ceramic Society, 1998.

[5] M. N. Rahamon, Ceramic Processing and Sintering, Taylor and Francis Group, Boca Raton, Fla, USA, 2nd edition, 2004.

[6] J. Hlavac, The Technology of Glass and Ceramics. An Introduction, Elsevier Science, 1983. 
[7] G. Ville and D. R. Ulrich, Ultrastructure Processing of Ceramics, Glasses and Composites, John Wiley \& Sons, 1984.

[8] C. J. Brinker and G. W. Scherer, The Physics and Chemistry of Sol-Gel Processing, Academic Press, 1994.

[9] K. Yoshida, H. Hyuga, N. Kondo, and H. Kita, "Synthesis of precursor for fibrous mullite powder by alkoxide hydrolysis method," Materials Science and Engineering B, vol. 173, no. 1-3, pp. 66-71, 2010.

[10] P. Padmaja, G. M. Anilkumar, P. Mukundan, G. Aruldhas, and K. G. K. Warrier, "Characterisation of stoichiometric sol-gel mullite by fourier transform infrared spectroscopy," International Journal of Inorganic Materials, vol. 3, no. 7, pp. 693-698, 2001.

[11] D. Ribero, R. Restrepo, C. Paucar, and C. García, "Highly refractory mullite obtained through the route of hydroxyhydrogels," Journal of Materials Processing Technology, vol. 209, no. 2, pp. 986-990, 2009.

[12] J. Li, H. Lin, J. Li, and J. Wu, "Effects of different potassium salts on the formation of mullite as the only crystal phase in kaolinite," Journal of the European Ceramic Society, vol. 29, no. 14, pp. 2929-2936, 2009. 

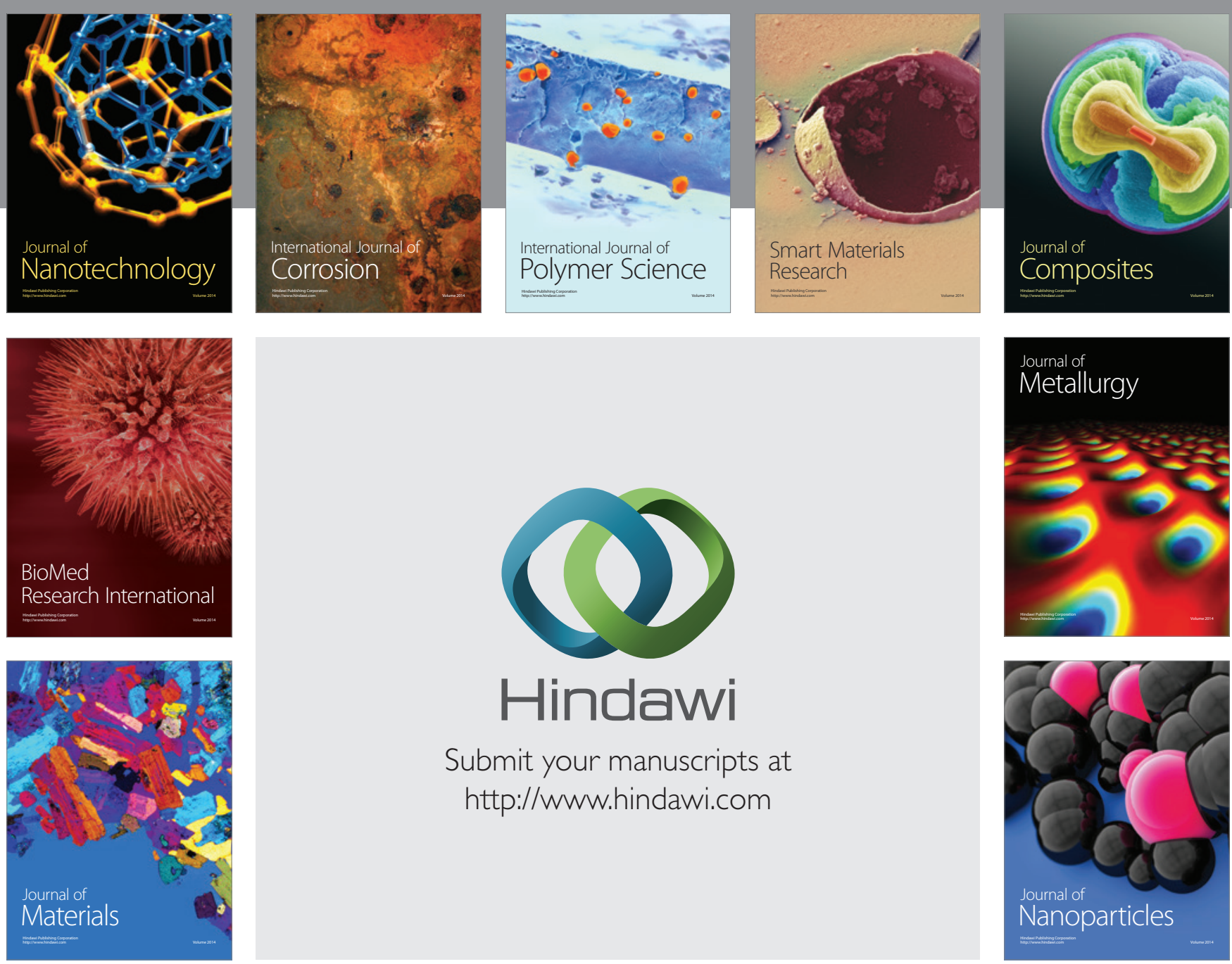

Submit your manuscripts at http://www.hindawi.com
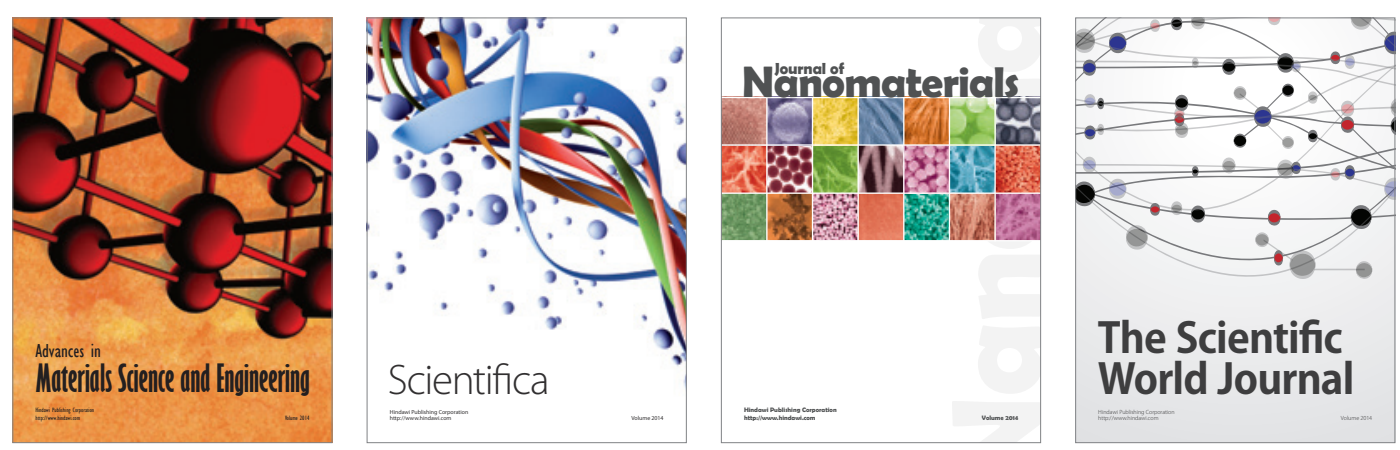

\section{The Scientific World Journal}
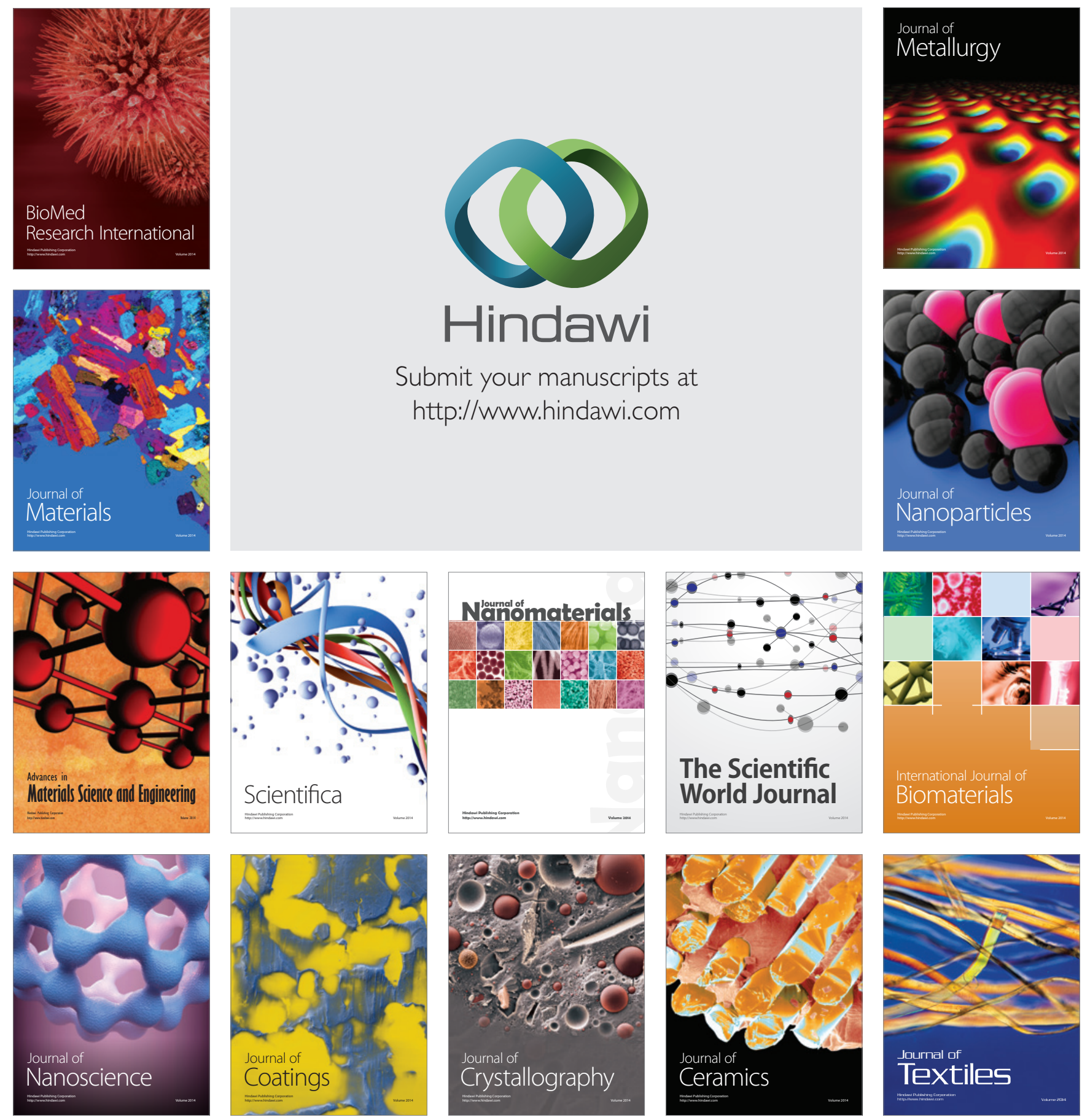